\title{
A EFICÁCIA HORIZONTAL DOS DIREITOS FUNDAMENTAIS NOS CONTRATOS DE DIREITO PRIVADO
}

\author{
HORIZONTAL EFFECTIVENESS OF FUNDAMENTAL RIGHTS IN \\ PRIVATE LAW CONTRACTS
}

\author{
Lorena de Melo Freitas ${ }^{1}$ \\ Ilton Garcia da Costa ${ }^{2}$ \\ Fernando Cesar Vellozo Lucaski ${ }^{3}$
}

\section{RESUMO}

O presente artigo tem como objetivo analisar as teorias que tratam da eficácia horizontal dos direitos fundamentais nas relações privadas e sua aplicação no direito brasileiro. Ao longo do trabalho serão exploradas posições doutrinárias pertinentes ao tema, o fenômeno da constitucionalização do direito civil e os princípios aplicáveis aos contratos, para a partir de então analisar a forma como os direitos fundamentais são interpretados nas relações entre particulares.

Palavras-Chave: Direitos fundamentais. Eficácia horizontal. Relações privadas.

\begin{abstract}
This article aims to analyze theories that deal with the horizontal efficacy of fundamental rights in private relations and their application in Brazilian law. Throughout the work will be explored doctrinal positions pertinent to the theme, the phenomenon of the constitutionalization of civil law and the principles applicable to contracts, from then on to analyze how fundamental rights are interpreted in relationships between individuals.
\end{abstract}

\footnotetext{
1Professora dedicação exclusiva da UFPB (Associada I), ensinando na Graduação (Hermenêutica Jurídica, Direito Internacional Privado) e Pós-Graduação em Direito - Mestrado e Doutorado (Metodologia, Teoria Geral do Direito). Membro do GT Ética e Cidadania da ANPOF. Graduada (UNICAP), Mestra e Doutora (UFPE) em Direito. Desenvolve pesquisas voltadas à atividade judicial desde o mestrado quando defendeu Dissertação intitulada ?Ideologia e direito: uma pesquisa empírica sobre a Associação Juízes para a Democracia? e no Doutorado com tese sobre a formação da decisão por juízes e tribunais sob título ?O realismo jurídico como pragmatismo: A retórica da tese realista de que direito é o que os juízes dizem que é direito?. Tem livros publicados e organizou obras coletivas sobre estas temáticas, tendo, para realização de suas atividades fundado o Grupo de Pesquisa ligado ao PPGCJ/UFPB: ?Realismo Jurídico?. Participa como pesquisadora de outros grupos de pesquisa ("Marxismo e Direito", "Pragmatismo Jurídico, Teorias da Justiça e Direitos Humanos" e "Fundamentos e Métodos do Pragmatismo: uma abordagem interdisciplinar dos fenômenos jurídicos") e tem como foco de pesquisa os seguintes temas: Realismo jurídico, ideologia, retórica, teoria geral, filosofia e sociologia do direito. A pesquisa de Pós-doutorado se intitulou: Espaços jurídicos emancipadores e inclusão como direito ao desenvolvimento sociopolítico: Uma crítica anisiana acerca das interfaces da pós-graduação com a educação básica em atenção à meta de 2007/2008 da CAPES.

${ }^{2}$ Doutor em Direito Civil pela Universidade do Estado do Rio de Janeiro - UERJ (2012). Mestre em Direito pela Universidade Federal do Paraná - UFPR (2001). Graduado em Direito pela Universidade Federal do Paraná (1995). Advogado. Professor da Escola da Magistratura do Paraná ? EMAP. Professor da Fundação Ministério Público do Estado do Paraná ? FEMPAR. Professor Permanente do Programa de Mestrado e Doutorado em Direito Empresarial e Cidadania do UNICURITIBA. Realiza estágio Pós-Doutoral na Universidade Nova de Lisboa (2016/2017). Tem experiência em: Direito Privado. Função Social da Empresa. Responsabilidade. Cidadania. 3 Mestrando em Direito Empresarial e Cidadania pela Faculdade de Direito de Curitiba.
} 
Keywords: Fundamental rights. Horizontal effectiveness. Private relations. 


\section{INTRODUÇÃO}

O espaço destinado para a disciplina dos direitos fundamentais evoluiu ao longo das diversas constituições adotadas no estado brasileiro, ganhando especial destaque na Constituição de 1988 que positivou diversos direitos e garantias ao cidadão, em especial no seu artigo $5^{\circ}$ que trouxe um rol de direitos e garantias com vistas, sobretudo, a proporcionar ao cidadão meios de defesa contra eventuais arbítrios estatais.

A opção do Constituinte originário em trazer extensivo rol de direitos e garantias fundamentais na constituição de 1988 , que não se limitam apenas ao artigo $5^{\circ}$, mas se encontram disciplinados ao longo de diversas passagens do texto, justifica-se pelo momento histórico que o Brasil enfrentava, pois estávamos em plena transição do regime ditatorial para a volta à democracia. Não é demais lembrar que as décadas em que o regime militar vigorou no Brasil foram marcadas por um tenebroso histórico de violações de liberdades e garantias dos cidadãos praticados pelo próprio Estado através de seus agentes e por particulares com o seu aval ou omissão, justificando então a preocupação de que a nova constituição representasse uma radical ruptura com esse sistema.

Mas para além de garantir direitos frente à atuação do estado existe uma crescente necessidade de se pensar a proteção dos direitos fundamentais também na relação entre particulares. De fato há muito tempo a doutrina vem defendendo a eficácia dos direitos fundamentais nas relações entre particulares, sob a premissa de que mesmo nas relações privadas é possível que se verifique um desequilíbrio capaz de subjugar uma das partes e provocar violações de direitos fundamentais.

Essa afirmativa é especialmente relevante no contexto de relações jurídicas onde existem partes vulneráveis, como por exemplo, nas relações de trabalho e contratos de consumo, mas também é válida e verificável em outras relações de natureza civil. De fato, mesmo em contratos de direito privado, onde é de vital importância a autonomia da vontade das partes, é necessário harmonizar os seus princípios com os mandamentos constitucionais.

A par desse contexto há uma crescente necessidade de se interpretar os institutos jurídicos de direito privado sob a ótica dos princípios constitucionais. Esse fenômeno embora não seja recente, ganhou evidente importância a partir da promulgação da Constituição de 1988.

Nesse contexto, o presente artigo tem como objetivo analisar as teorias que tratam da eficácia horizontal dos direitos fundamentais nas relações privadas, suas influências e 
aplicações no direito brasileiro, em contraposição aos princípios que regem os contratos privados.

\title{
2 DIREITOS FUNDAMENTAIS EFICÁCIA VERTICAL E HORIZONTAL
}

A Constituição Federal de 1988 instituiu um novo paradigma na proteção dos direitos fundamentais, trazendo ao longo do seu texto diversos dispositivos dedicados a esta proteção.

O contexto histórico de redemocratização e fim da ditadura militar que perdurou por décadas justificam uma relevante preocupação do Constituinte originário em destinar especial proteção aos cidadãos contra o abuso do poder estatal no texto constitucional. São diversos os dispositivos da Constituição destinados à proteção dos direitos fundamentais, merecendo destaque, o artigo $5^{\circ}$ que traz um rol de direitos considerados tão relevantes, que sequer podem ser objetos de emenda constitucional que tenha por objeto a sua alteração ou supressão.

Para contextualização, os direitos fundamentais são conceituados como direitos humanos positivados pela Constituição, tratam-se como explica MENDES (1998. p. 32) de:

\begin{abstract}
Os direitos são, a um só tempo, direitos subjetivos e elementos fundamentais da ordem constitucional objetiva. Enquanto direitos subjetivos, os direitos fundamentais outorgam aos titulares a possibilidade de impor os seus interesses em face dos órgãos obrigados. Na sua dimensão como elemento fundamental da ordem constitucional objetiva, os direitos fundamentais - tanto aqueles que não asseguram, primariamente, um direito subjetivo, quanto aqueles outros, concebidos como garantias individuais formam a base de um ordenamento jurídico de um Estado de direito democrático.
\end{abstract}

No âmbito da eficácia, os direitos fundamentais, historicamente concebidos sob a égide do estado liberal, tinham como primordial função uma espécie de proteção do cidadão contra o poder estatal, destinando-se, pois a limitar a influência do Estado nas suas relações com particulares, tratavam essencialmente do direito à liberdade, que exigiam uma não interferência. Nesse sentido é valiosa a lição de SARMENTO (2004, p. 27):

Dentro deste paradigma, os direitos fundamentais acabaram concebidos como limites para atuação dos governantes, em prol da liberdade dos governados. Eles demarcavam um campo no qual era vedada a interferência estatal, estabelecendo, desta forma, uma rígida fronteira entre o espaço da sociedade civil e o do Estado, entre a esfera privada e a pública, entre o jardim e a praça. Nesta dicotomia público/privado, a supremacia recaía sobre o segundo elemento do par, o que decorria da afirmação da superioridade do indivíduo sobre o grupo e sobre o Estado. 
Essa concepção formada acerca dos direitos fundamentais explica-se, sobretudo pela ideia de que o Estado não deveria interferir nas relações privadas, algo intimamente ligado ao liberalismo econômico, onde o Estado abdicava de sua atuação direta na economia, garantindo que os cidadãos fossem livres para nela atuar da forma que lhe fossem convenientes (SARMENTO. 2004, p. 28).

A partir da premissa de que os direitos fundamentais eram oponíveis apenas pelo particular em face do Estado, excluía-se de qualquer apreciação a aplicação dos direitos fundamentais em relações privadas. Essa concepção de que os direitos fundamentais têm como função atuar apenas no âmbito das relações público-privado é tida pela doutrina como eficácia vertical dos direitos fundamentais, como bem acentuado por LEITE (2011):

\footnotetext{
Destarte, é notório que os direitos fundamentais surgiram para resguardar as pessoas do arbítrio dos Poderes Públicos, é dizer, à época do constitucionalismo liberal clássico - quando surgiram as constituições revolucionárias do século XVIII -, a aplicabilidade desses direitos era oponível, tão somente, em face do Estado, como forma de proteção das liberdades individuais. A isso, convencionou-se chamar de eficácia vertical dos direitos fundamentais.
}

Contudo, é forçoso concluir que atualmente a limitação da eficácia dos direitos fundamentais as relações público-privado não é mais aceita, na medida em que há necessidade de tutela também nas relações entre particulares. Com efeito, na dinâmica da sociedade atual é importante reconhecer que em determinadas circunstâncias o particular pode atuar como violador de direitos fundamentais de outrem, por isso, é necessário se estabelecer a eficácia da proteção dos direitos fundamentais também nas relações privadas, hipótese concebida pela doutrina como eficácia horizontal dos direitos fundamentais.

A doutrina mais abalizada sobre o tema convencionou estabelecer três importantes concepções sobre o grau de aplicabilidade dos direitos fundamentais na relação privada, a teoria da ineficácia, a teoria da eficácia indireta ou mediata e a teoria da eficácia direta ou imediata.

A teoria que versa sobre a ineficácia dos direitos fundamentais sobre as relações privadas propugna que apenas o Estado é destinatário dessas normas, buscando fundamento na concepção clássica do estado liberal. Portanto, as relações entre particulares não poderiam ser analisadas sobre a ótica da proteção dos direitos fundamentais, afastando qualquer discussão nesse sentido. 
A teoria da ineficácia dos direitos fundamentais nas relações privadas tem larga aplicação no ordenamento jurídico dos Estados Unidos (state action doctrine) que estabelece que a proteção destinada pelos direitos fundamentais não podem ser invocadas quando a violação não parte do Estado, por entender que os particulares não são destinatários destas normas. Assim, no contexto norte-americano, salvo raras exceções, quando, por exemplo, o particular atua a mando do Estado, não é possível invocar a proteção dos direitos fundamentais nas relações privadas (SANTOS 2010). Essa teoria, todavia, praticamente se restringe ao direito norte-americano, não sendo aceita no Brasil, sobretudo por não ser compatível com as diretrizes constitucionais.

Por outro lado, a teoria da eficácia mediata ou indireta defende a ideia de que no âmbito das relações privadas a incidência dos direitos fundamentais deve ser considerada a partir dos instrumentos próprios do direito privado, cabendo ao legislador estabelecer parâmetros jurídicos para aplicação dos direitos fundamentais no âmbito das relações privadas e na ausência legal, restaria a Poder Judiciário preencher as lacunas a partir de outros instrumentos do direito privado (AZEVEDO. 2014).

A teoria da eficácia mediata ou indireta pressupõe ainda que em determinadas relações privadas o particular pode abdicar de determinados direitos, sobrelevando-se assim, a autonomia da vontade. A sua aplicação pressupõe ainda que o destinatário inicial é o Poder Legislativo, a quem compete efetivar os direitos fundamentais nas relações entre particulares. Nesse sentido a lição de SARMENTO (2004.p. 241):

\footnotetext{
Portanto, para os adeptos da teoria da eficácia indireta, cabe antes de tudo ao legislador privado a tarefa de mediar a aplicação dos direitos fundamentais sobre os particulares, estabelecendo um disciplina das relações privadas que se revele compatível com os valores constitucionais. Competiria ao legislador proteger os direitos fundamentais na esfera privada, mas sem descurar-se da tutela da autonomia da vontade. Portanto, caberia ao Legislativo proceder a uma ponderação entre interesses constitucionais em conflito, na qual lhe é concedida certa liberdade para acomodar os valores contrastantes, em consonância com a consciência social de cada época.
}

O entendimento defendido pela teoria da eficácia mediata ou indireta segundo SARMENTO (2004.p. 241) é de que existe uma espécie de hierarquia entre o Poder Legislativo e o Judiciário no tocante a proteção dos direitos fundamentais nas relações privadas. Dessa forma, no conflito entre direitos fundamentais e autonomia da vontade, caberia ao Poder Legislativo estabelecer os parâmetros para harmonização deste choque de interesses, enquanto que ao Poder Judiciário restaria apenas interpretar conceitos abertos e/ou genéricos definidos 
pela lei, em consonância com os direitos fundamentais e afastar as normas privadas que não fossem compatíveis com esses direitos.

Por fim, a teoria da eficácia mediata ou direta, em contraposição as demais teorias acima citadas, defende a concepção de que os direitos fundamentais possuem uma vertente subjetiva e que, portanto, incidem diretamente nas relações jurídicas, seja em âmbito público ou privado, com eficácia erga omnes e independente de qualquer atuação do Poder Legislativo. Essa eficácia direta se justificaria sob a premissa de que ameaças e violações a direitos fundamentais não ocorrem apenas pelo Estado, mas também por particulares, justificando assim a sua extensão SARMENTO (2004.p. 245).

É importante observarmos que, salvo a teoria da ineficácia acima citada, as demais partem da premissa comum de que o particular, no qual se incluem pessoas físicas e jurídicas, também pode agir como violador de direitos fundamentais. Essa premissa é de grande relevância em diversas relações jurídicas, como por exemplo, no direito do trabalho, direito civil em especial no tocante aos contratos, no direito societário entre outros, que, embora também sejam orientados por normas imperativas de ordem pública, tem prevalência da autonomia da vontade.

\section{O PRINCIPIO DA AUTONOMIA DA VONTADE NOS CONTRATOS}

Corolário do pensamento liberal econômico, a autonomia da vontade sempre foi um dos mais relevantes princípios que orientavam o contrato civil. Na lição de (LOPEZ. 2012. p. 28) a autonomia da vontade está relacionada com a possibilidade do particular estabelecer com quem contratar e definir amplamente os termos que irão reger o contrato.

Fundamental para a compreensão do conceito de autonomia da vontade e a relevância que assume perante os contratos são os ensinamentos de WALD (2006. p. 188):

\footnotetext{
A autonomia da vontade se apresenta sobre duas formas distintas, na lição dos dogmatistas modernos. Podendo revestir o aspecto de liberdade de contratar e da liberdade contratual. Liberdade de contratar é a faculdade de realizar ou não determinado contrato, enquanto liberdade contratual é a possibilidade de estabelecer o conteúdo do contrato.
}

No entanto, há muito tempo a concepção clássica do princípio da autonomia da vontade vem sendo mitigada, para compreender que o Estado deve intervir em determinadas 
relações, para garantir igualdade material e equilíbrio entre as partes contratantes. NUNES (2001) advoga a ideia de que existem três princípios contratuais fundamentais, que são a já citada autonomia da vontade, a supremacia da ordem pública e a força obrigatória dos contratos, que apenas sofrem limitação pelo dirigismo contratual, quando o Estado fixa normas mínimas e obrigatórias a ser incorporada a relação.

O dirigismo contratual é conceituado como uma intervenção do Estado na autonomia da vontade das partes, por meio de normas imperativas que visam estabelecer equilíbrio entre as partes. Assim, estabelece-se cláusulas mínimas ou obrigatórias que deverão ser observadas em determinadas relações jurídicas (MATOS. 2009. p. 124).

MATOS (2009. p. 123) esclarece ainda que o dirigismo contratual é resultado de uma vertente econômica destinada a sobrepor os interesses coletivos sobre os individuais, bem como da necessidade de reduzir o desequilíbrio entre as partes contratante, decorrentes do concentração de capital, além da notória opção do estado em intervir nas relações particulares.

Mas para além do dirigismo contratual o que se tem observado é que desde a promulgação da Constituição Federal de 1988 existe um crescente fenômeno de interpretação do direito cível a partir dos dispositivos constitucionais, algo que convencionou denominar de constitucionalização do direito civil. A Constitucionalização do direito civil é definida por MIRANDA (2009) como sendo:

\footnotetext{
Vê-se, portanto, que não veio a Constituição de 1988 regular o direito civil em lugar da legislação ordinária, ou tornar o direito civil constitucional, mas tão-somente dar segurança jurídica à própria existência de tais institutos (resguardando-os de eventual arbítrio do legislador), elevando-os a nível constitucional pela sua essencialidade em função da existência da pessoa humana, em sua dignidade. Ora, é necessário, para concretizar a dignidade da pessoa, a existência de sua liberdade; de um mínimo existencial, manifestado muitas vezes pela possibilidade de efetivação do consumo; da propriedade; da família; do fim da vida, já com idoso. Todos estes fatores são considerados pela Constituição como valores, devendo ser protegidos em seu texto, e efetivados ordinariamente pela lei e pela atividade judicial dos juízes.
}

FIUZA; MARQUES (2006) ponderam que a denominada constitucionalização do direito civil é uma técnica de interpretação, por meio da qual o destinatário da norma deve compreender os institutos de direito privado a partir da ótica dos princípios constitucionais. Destacam ainda os Autores, que a partir dessa técnica é possível ao Poder Judiciário exercer com mais propriedade o seu dever de guarda da Constituição e dos direitos fundamentais dos cidadãos: 
Trata-se de uma modalidade de interpretação que dá maior respaldo à força normativa da Constituição, possibilitando ao juiz considerar insubsistentes normas ordinárias contrárias ao texto maior, através do mecanismo do controle difuso de constitucionalidade. Reformula-se, assim, a hermenêutica tradicional, que interpretava o Código Civil ao lado da Constituição. As posições se alteram. O Código não está ao lado, mas abaixo. A Constituição há de ser seu fundamento.

No mesmo sentido PINTO (2009) destaca a importância da constitucionalização do direito civil para propiciar o controle de constitucionalidade das leis:

Como corolário, ocorreu a chamada constitucionalização do Direito que consistiu na irradiação dos valores albergados nos princípios e regras da Constituição para todo o ordenamento jurídico, principalmente através da jurisdição constitucional em seus diferentes níveis. As principais consequências dela resultantes foram a aplicação direta da Constituição a diversas situações, a inconstitucionalidade das normas incompatíveis com a Carta Magna e a interpretação das normas infraconstitucionais conforme o disposto na Constituição, que irá determinar-lhes o sentido e o alcance.

TEPEDINO (2003/2004) cita que a despeito das novas diretrizes contidas na Constituição Federal, a doutrina civilista aponta algumas críticas em relação a constitucionalização do direito civil, sintetizando tais criticas em quatro pontos abaixo destacados:

(i) os princípios constitucionais, mesmo tomados como preceitos normativos, constituem-se em normas de organização política e social e, portanto, valer-se deles para a regulamentação das relações jurídicas interindividuais traduziria verdadeiro salto sobre o legislador ordinário, ao qual é dado disciplinar o direito privado: (ii) a baixa concretude dos princípios constitucionais, suscitaria exagerada e por vezes perigosa subjetividade dos juízes; (iii) as normas constitucionais sujeitam-se a reformas, compromissos e contingências políticas, ao contrário das normas do direito privado, muito mais afeitas à estabilidade própria da sua dogmática, em grande parte herdada, quase de forma intacta, desde o direito romano; e (iv) o controle de merecimento de tutela imposto pela aplicação automática das normas constitucionais, para além do juízo de ilicitude dos atos em geral, representaria uma ingerência valorativa indevida nos espaços privados, reduzindo o campo das escolhas e liberdades individuais.

TEPEDINO (2003/2004) prossegue afirmando que este entendimento não encontra consonância com a atual ordem jurídica, que se funda, sobretudo, na dignidade da pessoa humana.

Assim, a par desse fenômeno de irradiação dos princípios constitucionais nas relações privadas, o direito contratual civil, como não poderia deixar de ser, também foi afetado. LOPEZ (2012. p. 22) destaca que o Código Civil de 2002, inspirado nas determinações 
constitucionais acerca dos direitos fundamentais, passou a conceber a busca pela justiça contratual, a partir da observância do princípio da confiança pelo qual deve se levar em conta a manifestação da vontade do declarante de forma objetiva, protegendo os direitos do seu destinatário de boa-fé. De fato a manifestação da vontade sempre foi o mote do direito contratual e anteriormente era concebida como absoluta, todavia, esse entendimento não se coaduna mais com a nova ordem constitucional.

Como se pode observar, como ocorre em todo direito privado a autonomia da vontade não é um direito absoluto e sofre limitações, na medida em que a liberdade de se estabelecer regramento para disciplinar uma determinada relação jurídica não pode ser feita em prejuízo a direitos fundamentais.

\section{EFICÁCIA HORIZONTAL E INTERFERÊNCIA NOS CONTRATOS}

$\mathrm{Na}$ linha dos que foi exposto nos tópicos anteriores é forçoso observamos que a problemática da incidência dos direitos fundamentais nas relações privadas está intrinsicamente relacionada com a amplitude desta interpretação, bem como com os critérios para definir em que ocasião um particular pode exigir em face de outro, a oponibilidade de determinado direito fundamental.

Neste ponto é importante destacarmos que, ainda que não exista um consenso sobre a melhor teoria a ser adotada na incidência das normas de direito fundamental no âmbito das relações privadas, é possível concluirmos pela sua adequação no âmbito do ordenamento jurídico brasileiro, afastando, portanto, a possibilidade de se sustentar a teoria da ineficácia. Isto porque, na dinâmica das relações atuais, é inafastável o reconhecimento de que o particular, ai considerando também as pessoas jurídicas de direito privado, podem agir como violador de direitos.

Corroborando com o exposto, SARMENTO (2004.p. 279) sustenta que a Constituição brasileira exclui a possibilidade de adotar a teoria difundida nos Estados Unidos da ineficácia, e igualmente, não se coaduna com a teoria da eficácia indireta, sendo a mais adequada a nossa realidade a teoria da eficácia direta, que permite a incidência dos direitos fundamentais nas relações privadas independente da existência de legislação ordinária ou esforço interpretativo pelo Judiciário das cláusulas gerais do direito privado.

No mesmo sentido sustenta NERY (2012): 
Nessa perspectiva, a jurisprudência no Brasil tem se orientado no sentido de admitir a eficácia direta e imediata dos direitos fundamentais nas relações entre particulares, independentemente da atuação do legislador ordinário ou do recurso à interpretação das cláusulas gerais do direito privado. "Esta, para nós, não é só uma questão de direito, mas também de ética e justiça.”

RUBIN (2001. p. 119), embora admita que a teoria da eficácia é compatível com nosso ordenamento jurídico, pondera pela necessidade de se estabelecer critérios para a sua aplicação, salientando que é preciso diferenciar os casos em que existe hipossuficiência entre os contratantes, quando então existiria uma maior incidência dos direitos fundamentais na relação privada. Nas relações contratuais onde não se observa a existência de hipossuficiência, somente poderia ocorrer a incidência se verificada a discriminação por sexo, raça, gênero, religião, etc., sendo vedada a oponibilidade dos direitos fundamentais nos demais casos, sob pena, de uma injusta interferência a autonomia da vontade.

Sem embargos acerca do posicionamento acima SARMENTO (2004.p. 289), entende que os direitos fundamentais devem incidir nas relações privadas independente do grau de igualdade entre as partes:

\footnotetext{
Para nós, por ouro lado, existe sempre uma vinculação direta dos particulares aos direitos fundamentais, independente da existência, ou não, de uma manifesta desigualdade de forças entre as partes nas relações jurídicas. Não apenas os grandes grupos empresariais, empregadores, associações, sindicatos e congêneres estão atrelados àqueles direitos, mas também o cidadão comum, nas relações paritárias que mantiver com outras pessoas. A questão da desigualdade material torna-se relevante apenas no momento em que se tiver que ponderar o direito em questão com a autonomia privada, conforme explicitaremos mais adiante.
}

A despeito das matrizes doutrinárias propugnarem em maior ou menor grau a eficácia horizontal dos direitos fundamentais nas relações privadas, permanece o questionamento sobre quais são os critérios que devem nortear a interpretação pelo Poder Judiciário. SARMENTO (2004.p. 332) pondera que em nessas relações heterogêneas, tais como famílias associações civis e empresas, que são reguladas por diferentes ramos do direito, com inúmeras regras normativas, é tarefa difícil se estabelecer um padrão teórico que abrigue a possibilidade de imposição de direitos fundamentais nestas relações. Prosseguindo, exemplifica essa dificuldade:

Assim, pode soar como muito "progressista" a proposta de incidência direta e incondicionada dos direitos sociais, políticos e difusos no campo privado, mas dificilmente alguém com bom senso advogaria a tese de que uma pessoa pobre, só 
pela ausência de posses, pudesse exigir um tratamento de saúde gratuito de um hospital privado qualquer, com o qual não mantivesse nenhum tipo de vínculo, ou ainda que um empregado, com base na Constituição, tivesse como pleitear o exercício do direito de voto numa assembleia de acionistas da empresa em que trabalha. $\mathrm{Na}$ verdade, parece-nos que a incidência dos direitos sociais, políticos e transindividuais no campo privado reveste-se de uma série de nuances, que procuraremos a seguir descrever, e depende, mais ainda do que a aplicação dos direitos individuais nas relações horizontais, se soluções tópicas, atentas às particularidades de cada caso.

No âmbito da jurisprudência, o Supremo Tribunal Federal no julgamento do emblemático Recurso Extraordinário 201.819/RJ reconheceu a eficácia direta dos direitos fundamentais nas relações privadas em detrimento da autonomia da vontade em contrato de associação. O caso tratava de pedido de recurso movido pela União Brasileira de Compositores - UBC, sociedade sem fins lucrativos, contra decisão do Tribunal de Justiça do Estado do Rio de Janeiro que reverteu a punição de exclusão de sócio, por violação ao direito a ampla defesa. No Recurso Extraordinário a UBC defendia a inaplicabilidade do direito constitucional a ampla defesa e prevalência das suas deposições estatutárias. O STF, todavia, entendeu pela plena incidência dos direitos fundamentais nas relações privadas.

Embora a decisão não defina claramente as balizas que devem nortear a aplicação da eficácia horizontal dos direitos fundamentais nas relações privadas, certo é que ela adota claramente a teoria da eficácia imediata, na medida em que observamos uma intervenção direta do Poder Judiciário em uma relação privada, com vistas a modificar os termos de um contrato.

\section{CONSIDERAÇÕES FINAIS}

A evolução das relações sociais e consequentemente do direito evidenciaram a necessidade de discussões sobre a forma como os direitos fundamentais devem ser aplicados e interpretados no âmbito das relações particulares, sobretudo nas relações contratuais, onde ainda se tem prevalência do princípio da autonomia da vontade e da força obrigatória dos contratos.

Nesse sentido, são de extrema relevância as discussões doutrinárias e jurisprudenciais acerca da eficácia horizontal dos direitos fundamentais nas relações privadas, sobretudo, diante do reconhecimento de que na atual dinâmica das relações sociais é factível que possam existir violações de direitos por particular em face de particular. 
Apesar de existir consenso sobre a necessidade de tutela de direitos fundamentais nas relações privadas e de que está afirmação decorre do próprio texto constitucional, ainda remanescem dúvidas sobre a amplitude que se deve conferir na aplicação prática, oscilando as intepretações entre a teoria da eficácia mediata e a teoria da eficácia imediata. No ordenamento jurídico brasileiro, como vimos nos tópicos anteriores, afasta-se a teoria da ineficácia, eis que a interpretação sistemática da constituição federal de 1988 impõe que os direitos fundamentais sejam observados tanto pelo Estado como pelos particulares, ainda que em relações estritamente privadas.

No âmbito prático, o Supremo Tribunal Federal instado a se manifestar sobre o tema reconheceu a eficácia horizontal imediata dos direitos fundamentais em uma relação privada, sem, contudo definir parâmetros mais sólidos de como essa teoria deve ser aplicada em casos análogos. Portanto, ainda que este precedente do Supremo Tribunal Federal seja importante para as discussões sobre o tema, remanesce a necessidade de se estabelecer critérios objetivos que possam ser aplicados nos demais casos.

\section{REFERÊNCIAS}

AZEVEDO, Fabiana Neiva Nunes. Eficácia dos direitos fundamentais nas relações privadas. Conteúdo Juridico, Brasília-DF: 24 dez. 2014. Disponível em: $<$ http://www.conteudojuridico.com.br/?artigos\&ver=2.51733\&seo=1>. Acesso em: 03 jul. 2018.

BRASIL. Supremo Tribunal Federal. Recurso Extraordinário n 201.819/RJ. Relator para o acórdão Ministro Gilmar Mendes. Disponível em http://stf.jus.br/portal/jurisprudencia/listarJurisprudencia.asp?s 1=\%28RE\%24\%2ESCLA\%2E $+\mathrm{E}+201819 \%$ 2ENUME\%2E\%29+OU+\%28RE\%2EACMS\%2E+ADJ2+201819\%2EACMS $\% 2 \mathrm{E} \% 29 \&$ base=baseAcordaos\&url=http://tinyurl.com/be4uyr4 Acesso em 03 de julho de 2018.

FIUZA, Cézar; MARQUES, Emanuel Adilson. Constitucionalização do direito das obrigações. Revista brasileira de direito constitucional, São Paulo, v. 4, n. 8, p. 87-108, jul./dez. 2006. Disponível em: <http://bdjur.stj.jus.br/dspace/handle/2011/26600〉. Acesso em: 29 de junho de 2018.

JÚNIOR, Marcos Augusto de Albuquerque Ehrhardt; TORRES, Marcio Roberto. Direitos Fundamentais e as Relações Privadas: Superando a (Pseudo) Tensão entre Aplicabilidade Direta e Eficácia Indireta para Além do Patrimônio. Revista Juridica, [S.1.], v. 53, n. 4, p. 326 356, fev. 2020. ISSN 2316-753X. Disponível em: <http://revista.unicuritiba.edu.br/index.php/RevJur/article/view/3222/371371738>. Acesso em: 21 abr. 2020. doi:http://dx.doi.org/10.21902/revistajur.2316-753X.v53i4.3222. 
LEITE, Samuel Pinheiro. O efeito perante terceiros dos direitos fundamentais e sua aplicação na ordem constitucional brasileira. Revista Direito e Liberdade - ESMARN - v. 13, n. 2, p. 345 $-370-$ jul/dez 2011.

LOPEZ, Teresa Ancona. Princípios contratuais in contratos empresariais: fundamentos em princípios dos contratos empresariais/ Wanderley Fernandes, coordenador $-2^{\mathrm{a}}$ ed. São Paulo: saraiva, 2012.

MATOS, Eneas de Oliveira. Controle de cláusulas abusivas no código de defesa do consumidor: um exemplo de dirigismo contratual no direito positivo brasileiro. in contratos empresariais: fundamentos em princípios dos contratos empresariais/ Wanderley Fernandes, coordenador $-2^{\mathrm{a}}$ ed. São PAULO: saraiva, 2012.

MENDES, Gilmar Ferreira. Direitos fundamentais e controle de constitucionalidade: estudos de direito constitucional. Celso Bastos editor. São Paulo: Instituto Brasileiro de Direito Constitucional. 1998.

MIRANDA, Roberta Drehmer de. Algumas notas sobre a "constitucionalização" do direito privado. Revista Eletrônica do Curso de Direito da UFSM, Santa Maria, v. 4, n. 3, nov. 2009. Disponível em: <http://bdjur.stj.jus.br/dspace/handle/2011/40755>. Acesso em 26 de junho de 2018.

NERY, Liliana Lopes. A eficácia dos direitos fundamentais na ordem jurídica privada. 2012. Dissertação (Mestrado) Universidade Federal de Minas Gerais. Minas Gerais. Acesso em 03 de julho de 2018.

NUNES, Cláudio Pedrosa. Os princípios fundamentais do regime contratual. Revista do Tribunal Regional do Trabalho do $13^{\text {a }}$ Região, João Pessoa, v. 9, n. 1, p. 23-31, 2001. Disponível em: <http://bdjur.stj.jus.br//dspace/handle/2011/19737>. Acesso em: 25 de junho de 2018.

PINTO, Emmanuel Roberto Girão de Castro. A vinculação dos particulares aos direitos fundamentais. Themis : Revista da ESMEC, Fortaleza, v. 6, n. 2, p. 165-188, ago./dez. 2008. Disponível em: <http://bdjur.stj.jus.br/dspace/handle/2011/26255>. Acesso em: 30 de junho de 2018.

RUBIN, Daniel Sperb. Direito Privado e Constituição - Contratos e Direitos fundamentais. Revista do Ministério Público. Rio Grande do Sul, vol. 44, p 83-121.

SANTOS, Simielle Barros dos. A eficácia de direitos fundamentais nas relações privadas: critérios objetivos para uma incidência imediata. Disponível em $<$ https://bdjur.stj.jus.br/jspui/bitstream/2011/41462/eficacia_direitos_fundamentais_santos.pdf $>$ Acesso em 24 de junho de 2018.

SARMENTO, Daniel. Direitos Fundamentais e Relações Privadas. Ed. Lumen Juris. Rio de Janeiro: 2004.

TEPEDINO, Gustavo. Normas constitucionais e direito civil. Faculdade de Direito de Campos, Campos dos Goytacazes, RJ, v. 4/5, n. 4/5, p. 167-175, 2003-2004. Disponível em: <http://bdjur.stj.jus.br/dspace/handle/2011/25727>. Acesso em: 01 de julho de 2018. 
WALD, Arnoldo. Obrigações e contratos. 17. Ed. rev., ampl. e atual. de acordo com o Código civil de 2002,- São PAULO: Saraiva, 2006. 